\title{
Razón evaluadora y escenarios del juicio educativo
}

\author{
Evaluative reason and educative judgment scenarios
}

\section{Facundo Giuliano ${ }^{1}$}

Fecha de recepción: 30-09-2019

Fecha de aceptación:3-02-2020

\begin{abstract}
Subconscientemente, la muchedumbre llegó a comprender que los tribunales se regían por preceptos extraños a la vida y la naturaleza de las cosas; y aunque cediera para acomodarse a las exigencias de esa vasta realidad omitida, las fuerzas primarias produjeron invisibles dislocaciones en el sistema.
\end{abstract}

Ezequiel Martínez Estrada, Radiografía de la pampa (1933).

\begin{abstract}
Resumen
El presente ensayo intenta explorar las diferentes formas que toma la razón evaluadora y sus presupuestos en los escenarios del juicio educativo, considerando algunas de las distintas tradiciones literarias, filosóficas y pedagógicas de las que se nutre y que contribuyen a su expansión actual. La travesía propuesta, que busca alimentar una crítica de la razón evaluadora, recorrerá algunas obras en las que se abordan elementos constitutivos de la racionalidad en cuestión. De esta manera, al tiempo que se detectan algunas problemáticas en la progresión (y contradicción) argumental pro-evaluativa de algunas obras del campo filosófico-educativo, se ofrecen contraposiciones que permitan trazar un horizonte otro para interrumpir la sinonimia que la modernidad/colonialidad instaló entre educación y evaluación. Por último, los pensamientos que se vuelcan en este escrito intentan contribuir a desnudar las lógicas crueles más solapadas que suelen imperar en enunciados cuyos efectos performativos infligen violencias en nombre de determinada moral. Esa moral involucra imperativos categóricos que exigen, entre otros aspectos, medidas específicas, tactos invasivos y ocupaciones (perversas) del lugar de otros, lo cual desfigura la función docente en una mera pragmática enjuiciadora y hace del enseñar una mera razón para evaluar. Palabras claves: razón evaluadora, juicio educativo, colonialidad pedagógica, filosofía de la educación, ética.
\end{abstract}

\begin{abstract}
The present essay tries to explore the different forms that the evaluative reason takes and its budgets in the educational judgment scenarios, considering some of the different traditions (literary, philosophical and pedagogical) from which it nourishes and contributes to its current expansion. The proposed journey, which seeks to feed a critique of the evaluative reason, will cover some works that address constitutive elements of the rationality in question. In this way, while some problems are detected in the pro-evaluative plot progression (and contradiction) of some works of the philosophical-educational field, contrapositions are offered that allow tracing one horizon to interrupt the synonymy that modernity/coloniality installed between education and evaluation. Finally, the thoughts that turn in this writing try to contribute to undress the most overlapping cruel logics that usually prevail in statements whose performative effects inflict violence in the name of a certain moral. That moral involves categorical imperatives that require, among other things, specific measures, invasive touches and occupations (perverse) of the place of others, which disfigures the teaching function in a mere pragmatic prosecutor and makes teaching a mere reason to evaluate. Keywords: evaluative reason, educative judgment, pedagogic coloniality, philosophy of education, ethics.
\end{abstract}

\footnotetext{
1 Licenciado en Ciencias de la Educación. Consejo Nacional de Investigaciones Científicas y Técnicas. Ministerio de Ciencia, Tecnología e Innovación de la Nación. Argentina. Correo electrónico: giulianofacundo@gmail.com
} 


\section{Obertura: caer en la cuenta (y levantarse)}

Si se aguza el oído y se sensibiliza la piel, a menudo pueden escucharse en el lenguaje educativo los ecos y resonancias, así como pueden notarse las marcas o cicatrices, del páthei máthos: esa idea griega de aprender de una prueba o una lección que implica un padecimiento, que involucra algún sufrimiento. Así es que se insta a "rendir cuentas", a "dar(se) cuenta" o a "caer en la cuenta" sin dejar margen de levantamiento ni lugar para salirse de la "cuenta", para irse del lugar sin pagar la "cuenta", para no ocupar siempre el lugar de quien debe saldar (o cobrar) "cuentas". La educación quizá sea uno de los pocos espacio-tiempos que existen donde el "pedir a cuenta" no tiene sentido, a menos que se le haga entrar en el terreno del lucro y la mercancía donde todo se reduce a meras transacciones con su correspondiente requerimiento de perfección disfrazado de calidad y eficiencia.

Así se asiste al florecimiento y la diseminación constantes de la evaluación (y su tipo de racionalidad) que hace caer en la cuentecilla in-saldable de un vacío que en apariencia no permite levantamiento alguno. O peor: la caída en un banquillo de tribunal sin ninguna presunción de inocencia y una declaración directa de culpabilidad. ¿Desde dónde se montan estos escenarios? ¿Qué tradiciones sostienen sus estructuras? ¿Cuáles son sus maneras y sus formas habituales? Estas tal vez podrían ser algunas preguntas que permitan trazar un punto de inflexión y convoquen algún levantamiento. Levantarse de (y contra) la matematización existencial quizá podría romper el círculo vicioso de la razón evaluadora y los escenarios del juicio educativo que la conforman. Por ello, a continuación, se convida una travesía combativa por diferentes textualidades que alimentan la razón evaluadora y estructuran los escenarios del juicio educativo. De este modo, se comenzará por indagar algunas contradicciones que constituyen antagonismos (entre términos como los de singularidad y comparación, educación y fabricación, ética y moral, lectura y evaluación), para luego introducir la exploración de diferentes escenarios del juicio educativo mediados por distintas fuentes literarias, filosóficas y pedagógicas que los estructuran y contribuyen tanto a su expansión como a su naturalización.
En este contexto, se tomarán para el análisis y el debate algunas obras (en particular del filósofo de la educación español Fernando Bárcena) que ofrecen un importante panorama de las formas en que el juicio educativo se instala desde cierta filosofía y literatura en los discursos pedagógicos fortaleciendo la razón evaluadora.

\section{De la "prohibición de comparar" a la lectura evaluativa del mundo}

En este tiempo donde se refuerzan las ideas de control "público" o "democrático" de la vida escolar, tales ideas no pueden dejar de leerse en los términos modernos que las estructuran y las ubican en relación directa con la(s) competencia(s) y el management evaluativo de la vida que no es otra cosa que la razón (evaluadora) de ser del control sutil, solapado o "democrático" que traza una pedagogía a tono con la época:

...en la época moderna también debamos hablar de otra forma de «totalitarismo democrático», cuyo propósito y objeto es la gestión de la vida, su administración y puesta en circulación en el mercado bajo los nombres quizá menos temibles, pero no por ello menos crueles, de (...) esa jerga de la competitividad y la eficacia. Bajo este nuevo rostro, aparentemente más amable, (...) uno de sus efectos esenciales es controlar, para evitar sorpresas e incertidumbres (...) De ahí nacerá una pedagogía de la programación, de la evaluación, de la previsibilidad. Una pedagogía del poder. Una pedagogía tecnológica, en definitiva. (Bárcena y Mèlich, 2000, pp. 42-43)

Lo que esas ideas (evaluadoras) de control manifiestan tal vez no sea otra cosa que el hecho de que la modernidad, más que un tiempo histórico o una época determinada, es una retórica (Mignolo, 2010) que impone una lógica (colonial-totalitaria) de conocimiento de "los otros": gentes que no están en el espacio donde el tiempo y la historia "avanzan", un afuera "subdesarrollado" construido al tiempo en donde se monta un adentro supuestamente "superior" y "desarrollado", es decir, una jerarquía ligada a "lo nuevo", a "la excelencia", a lo "primero" o "único". Términos que "sugieren el deseo de ser fiel a una forma 
sistemática, evaluable y mensurable de las interacciones e intervenciones educativas" (Bárcena y Mèlich, 2000, p. 75), en otras palabras, la reducción de lo educativo a un mero trabajo de "fabricación" según el cual se programan ciertos objetivos donde la labor educativa consistiría en realizarlos acotando todo margen de sorpresa e improbabilidad. De aquí cómo el control y la evaluación (al principio, en medio y al final) sean fundamentales para esta retórica en la que la educación, como acción o sorpresa que rompería con lo previsto, no tenga otra opción más que funcionar como trabajo por objetivos.

Así pues, esta pedagogía de la evaluación o de la razón evaluadora $^{2}$ descuida lo insustituible, único e irrepetible existente en cada quién, razón por la que Bárcena y Mèlich (2000) advierten que si se entendiera la educación como un proceso controlado, controlable y evaluable "el sujeto de la educación..." (p. 77). Por otra parte, no puede olvidarse que, para ellos, el recuerdo de Auschwitz les hace pensar la singularidad como la "prohibición de comparar" (Bárcena y Mèlich, 2000, p. 17) -un recuerdo demasiado fresco y cercano en el tiempo que tendría que convivir exactamente al lado del Otro (tan ocluido en las narrativas éticas del siglo XX), que refiere al recuerdo de las millones de muertes causadas por la Conquista y colonización de las Américas porque sobre esas muertes se ha construido la "condición humana" en la época moderna tan presente en la idea de civilidad y en la "cultura de la formación"-.

De modo que un antagonismo se traza entre la singularidad como prohibición de comparar y el gobierno universal del logos con su unidad totalitaria, esa "Unidad del Todo", de la Totalidad, que "no admite lo distinto, la ruptura del orden, lo no previsto, no evaluable o controlable. (...) El trabajo funciona según el logos (la lógica) de la totalidad: evaluación final, control del proceso" (Bárcena y Mèlich, 2000, p. 82). Bajo esta lógica, que no es otra que la misma de la colonialidad, hasta el tiempo se mensura, se cuantifica y, por lo mismo, se niega. Por eso llama la atención cuando luego en un capítulo dedicado a explorar la relación entre educación y narración, se apoyan directamente en el planteo de Martha Nussbaum (1997), que ubica el acto de leer y evaluar lo leído como "éticamente valioso" precisamente porque su estructura exigiría tanto la "inmersión" como la "conversación crítica" e instaría a "comparar lo que hemos leído, no solo con nuestra experiencia, sino con las reacciones y argumentaciones de otros lectores” (p. 34, énfasis mío).

De repente, pareciera suspenderse la "prohibición de comparar" para hacerlo en relación con algo tan singular como la lectura, la propia experiencia, las reacciones y argumentaciones de otros lectores, apareciendo así la evaluación de la lectura como algo éticamente justificado en su valía, lo que les permite decir: "el trato con la literatura es políticamente fructífero a condición de que se dé una evaluación ética del texto en conversación con otros lectores y una confrontación con los argumentos derivados de la teoría moral y política" (Bárcena y Mèlich, 2000, p. 117, énfasis mío). Esto despierta bastantes interrogantes: ¿acaso el trato con la literatura no es políticamente fructífero en tanto posibilita dar lugar a cierta epojé, a cierta suspensión del juicio y un darle lugar a lo in-evaluable? ¿De qué teoría moral y política se estaría hablando para confrontar el trato con la literatura?

Es evidente que la confrontación de Paradiso de Lezama Lima (1976) no será la misma desde la teoría moral y política kantiana que desde la ética y la política de la liberación dusseliana. Además, la relación entre ética y evaluación necesitaría de un abordaje complementario en tanto se sostenga la convicción de que son dos términos antagónicos, siempre y cuando se hable de una ética diferenciada radicalmente de la moral o habitando sus márgenes y no de una ética-moral (más cerca de planteamientos como el de Nussbaum o el mismo idealismo alemán). Un dato para destacar es cómo en una nueva edición del libro, Bárcena y Mèlich (2014) afirman pensar que la ética no es la moral y aproximan algunas caracterizaciones que las diferencian. Sobre la moral, la señalan como ese "conjunto de procedimientos, de normas, de costumbres, de hábitos o de valores, propios de una cultura concreta en un momento determinado de su historia” (p. 13), donde la escuela no sería más que una de las instituciones encargadas de transmitirla en función de cierto adoctrinamiento (ciertas normas, principios y códigos, no éticos, sino morales).

2 Como puede pensarse siguiendo lo planteado en Giuliano (2019). 
Por otra parte, la ética se muestra como más propia de la educación porque se trata de un acontecimiento, de una respuesta a la demanda del otro en una situación inaudita e imprevisible, en un encuentro absolutamente singular y único que posterga o desplaza deberes y obligaciones para dar (lugar a) una respuesta que puede romper con marcos legales o morales previos e instituidos, por eso se trata de "una fisura, una quiebra, una herida" (p. 13) de (y en) lo legislado, de (y en) los marcos públicos (legales, jurídicos, morales), lo cual involucra un gesto de resistencia.

Ahora bien, luego de esta insoslayable diferenciación se hace difícil conciliar o juntar dos términos radicalmente opuestos como evaluación y ética, un término que impone un juicio junto a otro que impele a suspenderlo, algo que se parece más a un oxímoron que a alguna aporía con pretensión emancipatoria, en última instancia una apuesta pos-política que quisiera borrar el antagonismo irreductible e ineludible entre evaluación (producto de una lógica moral) y ética (producto de alguna resistencia). Una derecha hegeliana estaría gustosa en sostener el tercer término al modo de una "síntesis superadora" que palie el conflicto. Sin embargo, tal vez bastaría un ejercicio de la memoria (evocando las tragedias que no se pueden olvidar) para hallar la fractura en el tiempo y dar cuenta de que ninguna ética (por antigua que se diga), como ningún código jurídico anterior, habilita a evaluar o juzgar lo inconcebible.

Por eso no deja de ser sorprendente que la "capacidad de epojé" (de suspensión) que tiene la literatura en relación con el juicio y la evaluación sea trocada o convertida en su contrario para, siguiendo la propuesta de Ricoeur (1996), "explorar nuevos modos de evaluar", no abolir el juicio sino someterlo a "variaciones imaginativas propias de la ficción”, y "revivir modos de evaluar que continúan perteneciendo a nuestra humanidad profunda" (p. 167). De modo que la potencia de la narración ${ }^{3}$ es limitada a desplegarse en un espacio imaginario en el que las experiencias de pensamiento se unifican al modo hipotético según el cual se ejerce el juicio; no obstante, también se parte de promover la ética como modo de dar lugar a lo no evaluable -y, por ende, a cierta resistencia-, de la prohibición de comparar como modo de pensar la singularidad y del acto educativo como forma de contrarrestar la "fabricación" propia de la pedagogía de evaluar. Pues la transformación del sentir y el obrar del lector -o la lectora- no depende de "ejercicios de evaluación" a partir de los cuales podría ejercer su papel de "descubrimiento".

Quizá ahí radique la trampa en la que han caído (o promueven) Ricoeur y sus seguidores: leer, al igual que la experiencia de la lectura, no es (ni puede ser) sinónimo -ni estar cerca- de evaluar (y su tipo de racionalidad). Porque, si se recuerda a Nietzsche (2000) en El nacimiento de la tragedia, la lectura no tiene que ver con el Yo, ni con la prisa cronológica, ni con la búsqueda de algún resultado; evaluar, en cambio, siempre supone un Yo que intenta multiplicarse, resultado que ha de obtenerse solo bajo el imperativo de Cronos. Y es que leer (a diferencia de evaluar) necesita de la distracción, del perderse en una travesía sin destino ni objetivos. Una travesía donde acciones y personajes no acontecen para ser evaluados o para "explorar nuevos modos de evaluar", sino tan solo para leer, es decir, convidar "una sensación del mundo que se dejó escribir en un gesto indescifrable" y esa sensación "no es una cifra, es un movimiento: saltos, tropezones, virajes, encrucijadas, verdades a prueba de milagros, milagros que se cuecen sin verdades a la vista" (Skliar, 2011, p. 232). ¿En qué teatro se montan entonces los escenarios que reducen la sensación a la cifra y la lectura a juicios que redundan en resultados económicamente viables? Con Artaud (2013) bien

\footnotetext{
3 El asunto podría esclarecerse o complicarse en parte cuando se dice que la función política del narrador es "aceptar las cosas tal y como son", lo que no equivaldría a justificación ni a perdón, pero sería "reconciliación, búsqueda del sentido de lo que acaece, una suerte de veracidad, de la cual nace la facultad de juzgar" (Bárcena, 2006, p. 252). Esta concepción sigue siendo problemática primero porque quien narra, ya sea en algún registro literario o histórico, no es un mero descriptor imparcial de sucesos; segundo, porque si hay algo que enseña la literatura y la historiografía es que su función es precisamente la contraria a la de "aceptar las cosas tal y como son"; tercero, por más sentido o veracidad que se busque, las partes que divide un antagonismo literario o histórico no podrán jamás reconciliarse a partir de un juicio porque eso sería la liquidación de lo político.
} 
podría responderse "El teatro de la crueldad”, y dejar trazada una segunda intención: "Terminar con el juicio de nuestros actos (...) como para indicar que el orden rítmico de las cosas y de la suerte han cambiado su curso" (p. 71).

\section{Escenarios literarios, filosóficos y pedagógicos del juicio educativo}

En esta sección se explorarán los escenarios del juicio educativo que tienden a justificarse (o naturalizarse) desde posiciones literarias, filosóficas y pedagógicas. En este marco, al mismo tiempo que se indagan diferentes escenas y personajes propios de estos escenarios, se convidan contraposiciones que buscan abrir sentidos para desmantelar las estructuras robustas sobre las que se montan.

\subsection{El juicio justificado desde ciertas literaturas: posiciones y contraposiciones}

La que se dice "nuestra humanidad más profunda" no puede estar atada a revivir modos de evaluar porque es ahí precisamente donde habita la colonialidad, la misma que hizo de la imaginación mercancía y de la fantasía el fantasma que, en aras de algún descubrimiento, solo incurrió en siglos de encubrimiento. Por eso leer no puede atarse a evaluar, y si alguien verdaderamente da la posibilidad de abrir un libro no puede ser para someter a juicio inquisidor de lo que se debería leer o de lo que se debería ser, por más hipotético que el modo se pretenda. Pero hay cierta literatura, como hay cierta filosofía, cierta pedagogía y psicología, que promueven el juicio.

En relación con la literatura, y profundizando la expresión de la pulsión evaluadora que aparece solapada sintomáticamente en el acápite precedente, Bárcena (2005) ofrece un claro ejemplo donde aborda el asunto. Se trata de La montaña mágica, donde Thomas Mann (2005) escribe que "Es preciso juzgar" y "Para eso la naturaleza nos ha dado ojos y cerebro" (p. 85), a la vez que reconoce en los humanistas los "únicos depositarios" de la tradición inherente a la dignidad y la belleza humana (razón por la cual no habría que desposeerles de su función de educadores). Bárcena (2005) ve en ello la relación entre el juicio y la "vocación pedagógica" del humanismo, pero sin poner en cuestión lo dado, la naturaleza de lo dado y la formación cultural de la mirada que enjuicia. Asimismo, también se pasan por alto las exclusiones sobre las que se monta la entronización de los "únicos depositarios" de cierta categoría de "Lo Humano", de "La Dignidad" y de "La Belleza". Y es que, aunque la naturaleza haya dado piernas al ser humano, no por ello va a patear a sus adversarios..., y aunque no se haya sentido "el llamado" o la inspiración procedente de Dios para llevar una forma de vida (un modo de significar lo que la palabra "vocación" quiere decir), lejos se está aquí de acordar con que tal “invitación” de Mann tendría que ver con que docentes “se tomen la enseñanza en serio” (Bárcena, 2005, p. 180).

Pues, tal como Deleuze (1996) lo observa, de la tragedia griega a la filosofía moderna hay toda una doctrina del juicio que se va elaborando y desarrollando, en la que lo trágico no es tanto la acción como el juicio. Con este planteamiento, así como la tragedia griega instaura primero un tribunal, Deleuze encuentra que Kant (1977) no inventa una verdadera crítica del juicio ya que termina por erigir un fantástico tribunal subjetivo. Por ello, se interesa por quienes tuvieron que padecer singularmente a causa del juicio y experimentaron ese punto en el que acusación, deliberación y condena se confunden infinitamente. Tal interés vertebrará su texto "Para acabar de una vez con el juicio", que aquí se tomará como una invitación necesaria en tanto y en cuanto se pretenda hacer del juicio el leitmotiv de la educación y la enseñanza.

Deleuze (1996) halla que Nietzsche (1997) supo poner de manifiesto la condición del juicio (por ej., en el libro segundo de la Genealogía de la moral o en el pasaje 42 de El Anticristo), esta es, la conciencia de tener una deuda impagable o "infinita" a partir de la cual alguien recurre al juicio, es juzgable o juzga y constituye cierta "doctrina del juicio". En D. H. Lawrence (2006) encuentra el "Poder de juzgar" como nueva forma de poder inventada por el cristianismo e instancia última de sometimiento (juicio final). En Kafka (2013), la "absolución aparente" o el "aplazamiento ilimitado" hacen que los jueces se mantengan más allá de la experiencia y concepción, a diferencia de Artaud (2013), que opondrá al infinito la operación de acabar de una vez con el juicio de Dios. 
No obstante, en estas cuatro figuras, Deleuze (1996) detecta la "lógica del juicio" en estrecha relación con la psicología del sacerdote que inventa "la más tenebrosa organización: quiero juzgar, tengo que juzgar...” (p. 177). En este sentido, la "doctrina del juicio", aunque aparente suavidad, siempre condena a "un avasallamiento sin fin y anula cualquier proceso liberatorio" (Deleuze, 1996, p. 179), porque sus elementos se agrupan en conjuntos que tienen características comunes y un fin determinado lotes, dirá Deleuze, que califican a las gentes para tal o cual forma, para tal o cual fin orgánico (como pensar que si se tiene ojos y cerebro ha de ser para juzgar)-. Así, el juicio divide la existencia en lotes y se traza una circularidad cuando los sujetos

juzgan en tanto que valoran su propio lote, y son juzgados en tanto que una forma confirma o destituye su pretensión. Son juzgados al mismo tiempo que juzgan, y los placeres de juzgar o ser juzgado son los mismos. (...) En última instancia, otorgarse un lote y castigarse uno mismo se convierte en los caracteres del nuevo juicio o de la tragedia moderna. Ya no hay más que juicio, $\mathrm{y}$ todo juicio se ejerce sobre un juicio. (Deleuze, 1996, p. 180)

El afán de juzgar, siempre en nombre de unos "valores superiores", tiene como base ese agrupamiento en función de un fin que verifica o destituye pretensiones al tiempo que delimita cierta seducción en función de la tarea que supone, una labor que implica cierta postura de placer/ poder y multiplica el juicio en sí mismo. De este modo, los lotes delimitan formas y el juicio vigila que las pretensiones no excedan las determinaciones de cada lote, de cada conjunto determinado (epistémica y ontológicamente) para un fin. Si la "tragedia moderna" está hecha de lotes que se auto-juzgan y auto-castigan, podría coincidirse con Bárcena (2001) en La esfinge muda cuando señala a la vigilancia como un rasgo intrínseco de la modernidad cuya tendencia al control no solo se evidencia en sus lógicas (identitarias-evaluativas) de identificación, sino en la extensión del poder administrativo que se plasma en los procesos de supervisión. Como la "policía del pensamiento" de Orwell (1995), la "invitación” de Mann (2005) confirma una organización, verifica un organismo, muestra un cuerpo organizado sin el cual el juicio no podría ejercerse, la naturaleza (una forma de deidad) dio ojos y cerebro y por eso es preciso juzgar.

El juicio requiere organización (porque actúa a través de ella) y podría decirse que el "loteo" es su manera predilecta, llegando hasta la organización corporal: "los órganos son jueces y juzgados, y el juicio de Dios es precisamente el poder de organizar hasta el infinito. De ahí la relación del juicio con los órganos del sentido" (Deleuze, 1996, p. 182). Como si ya la lógica y la doctrina del juicio estuviera introyectada en la configuración orgánica del propio cuerpo, una salida deleuzeana se encuentra en Artaud (2013) y su idea de cuerpo sin órganos como manera de sustraerse a esa organización corporal juzgativa y su pulsión evaluadora. Atravesado por una potente vitalidad no orgánica, el cuerpo sin órganos se caracteriza por tratarse de una corporalidad afectiva, intensiva y anarquista, compuesta de polos, zonas, umbrales y gradientes desde donde se instala la lucha "contra el juicio, contra sus instancias y sus personajes. Pero, más profundamente, el propio luchador es la lucha, entre sus propias partes, entre las fuerzas que subyugan o son subyugadas, entre las potencias que expresan estas relaciones de fuerzas" (Deleuze, 1996, pp. 182-184). Esta lucha-entre, además de determinar la composición de fuerzas de quien disputa, implica un proceso de apropiación, de enriquecimiento y suma de nuevas fuerzas para devenir en un nuevo conjunto que expresa la vitalidad de un "querer-vivir obstinado, tozudo, indomable", a ratos con terquedad o porfía, como principal forma de diferenciación de la vida orgánica.

4 De esta manera Deleuze (1996) caracteriza al recién nacido, con quien solo se podría tener una relación afectiva, atlética, impersonal, vital, algo que podría tomarse como sede lucha y forma de relación para una educación no enjuiciadora. 


\subsection{El juicio justificado desde ciertas filosofías: posiciones y contraposiciones}

En relación con la filosofía, el señalamiento de Gadamer (1999), en su libro Verdad y método, sobre la idea de Bildung (formación) como esa especificidad de las "ciencias del espíritu" que en la tradición ilustrada alemana es lo que las constituye en saber, es un importante ejemplo de una tradición epistémica-educativa montada en íntima relación con el juicio. Para Bárcena (2005) resulta fácil encontrar la "ubicación original" de la pedagogía en tal tradición humanista y, siguiendo a Gadamer (1999), señala los conceptos básicos de ella donde no puede soslayarse que, junto con esa idea de formación, se apunta a tres conceptos fundamentales para tal tradición: sentido común, capacidad de juicio y gusto. En este marco, resulta interesante para la discusión explorar algunos efectos de la adscripción pedagógica al texto gadameriano, como puede notarse en Bárcena (2005), que termina por reivindicar el idealismo de Kant en relación con el juicio y olvida su posición anterior que señalaba al idealismo como incapaz de entender la singularidad porque "con ello habría negado el universal gobierno del logos”, esa "Unidad del Todo, de la Totalidad" que "no admite lo distinto, la ruptura del orden, lo no previsto, no evaluable o no controlable" (Bárcena y Mèlich, 2000, p. 82).

De modo que, si en la postura anterior se visualizaba el juicio y la evaluación como parte de esa "fabricación" que hace del educar una mera labor pragmática de objetivosfines, ahora la "facultad de juzgar" aparece como: a) manifestación del "saber práctico"; b) expresión de un pensamiento propio e "independiente"; c) determinación de la acción, bajo condiciones de incertidumbre, o "voluntad que expresa un pensar para el otro (el sujeto que se educa o que aprende)” (Bárcena, 2005, p. 181); d) facultad política y praxis pedagógica. Así, la educación como "actividad práctica" o modalidad específica de acción "se resuelve tomando decisiones, haciendo elecciones y constituyendo juicios", lo que hace de la docencia una actuación que "inserta un nuevo comienzo en la secuencia de lo aparentemente calculable" y requiere de un espectador que "mira lo que hay" (Bárcena, 2005, p. 181, énfasis mío). Esta mirada podría pensarse como estructurante del escenario en tanto es mencionada como una condición impuesta para la práctica del juicio como facultad política y praxis pedagógica, precisamente porque, tal como señala Bárcena (2005) en su observación del vocablo alemán para la palabra 'juicio' (Urteil), es un concepto relacionado con el "placer meramente contemplativo", con un goce inactivo, pero que unido a fuerza, facultad o poder (Krafi) da como resultado la capacidad de juzgar (Urteilskrafi), cuyos prefijos y derivados llevan al juzgar asociado a la decisión (de donde se podría pensar la referencia a la sentencia o condena), al origen (Ur) y a (teilen) "la división primaria del discernir o diferenciar entre una cosa y otra” (p. 181). (Se enfatiza cosa porque la facultad de juzgar, como parte fundamental de la razón evaluadora, se mueve a partir de una lógica de cosificación y, en educación, ello impacta produciendo sentencias o condenas para cualquier sujeto constituido en cosa evaluable-juzgable).

Desde esa postura, el poder de juzgar (o "discernir") no derivaría de "una conciencia señorial que sólo entiende lo que puede prever" sino de "una sensibilidad que puede diferenciar y distinguir un sentido allí donde el entendimiento no alcanza" (Bárcena, 2005, p. 181). Aquí es donde entra Kant confiando tal poder o facultad en el gusto como "capacidad estética" que conduce un saber sensible que sería propio del espectador -alguien que "está destinado a ver, a mirar, a contemplar" (Bárcena, 2005, p. 181)-. En este sentido, se proyecta el "juicio pedagógico" como facultad estética, "un término sensible que, dentro de la acción, nos ayuda a ver lo que hacemos" (Bárcena, 2005, p. 181), pero si el juicio requiere de alguien que "especte", que mire o contemple (pasivamente) como destino previamente marcado para su lugar, ¿por qué el juicio pedagógico no involucraría cierta conciencia sensorial que solo entiende lo que puede pre-ver, lo que se sitúa antes de una experiencia en el sentido de que los lugares de esta ya están previamente determinados en la estructura de la escena?

Alguien podría sentirse tentado a recordar a Rancière (2010) cuando en El espectador emancipado dice que oposiciones como mirar/saber, apariencia/realidad, actividad/pasividad, no hacen más que distribuir a priori las posiciones (e imposiciones), las capacidades e incapacidades ligadas a tales lugares, que encarnan 
la desigualdad de la que se comienza a emanciparse cuando se cuestionan las oposiciones (comenzando quizá por la de mirar y actuar, donde mirar puede ser una acción que transforme tal distribución); o sea, cuando se evidencia críticamente que ciertas maneras de estructurar las relaciones del decir, el ver y el hacer pertenecen a la estructura (colonial) de la dominación y la sujeción. Pues se trata de una manera de lucha contra el juicio, contra el embrutecimiento que supone esa capacidad o fuerza que va impune e idéntica de un lado a otro y no ayuda a entender que cualquiera es actor y espectador de su historia que, además, se teje con hilos de una trama comunitaria.

\subsection{El juicio justificado desde ciertas pedagogías: posiciones y contraposiciones}

Bárcena (2005) sigue la doctrina del juicio ${ }^{5}$ kantiana y apuesta por trasladarla directamente a la educación y la pedagogía, en particular a la "experiencia reflexiva" que daría marco a los escenarios del juicio. Así pueden encontrarse los juicios "determinantes" (cuando se parte de una regla general o principio universal y se subsume a ella toda singularidad), que no gozan de buena prensa, y los juicios "reflexionantes" (cuando se juzga lo singular en ausencia de una regla general o universal), que no serían una habilidad lógica como el primero sino una destreza práctica que trata de "saber combinar lo singular del acontecimiento con lo universal de lo que se carece" (Bárcena, 2005, p. 182). Si en la primera forma se calcula o deduce, en la segunda se reflexiona articulando pensamiento y acción, se pasa de la teoría a la práctica bajo la primacía del razonamiento (que no sería más que someter el acontecimiento o la singularidad al gobierno universal del logos). De este último, podría subrayarse un aspecto destacable del planteo según el cual la facultad de juzgar nadie puede enseñarla, aunque sí puedan explicarse cuáles son los principios o reglas, "saber usarlas" requiere de un "arte especial" que Bárcena (2005) llama "tacto pedagógico” -como traducción práctica de dicha facultad a los escenarios educativos-.

En esa combinación de lo singular con lo universal de lo que se carecería se halla un punto clave, puesto que lo universal puede estar (momentáneamente) ausente, pero se le requiere para la combinatoria, se le convoca, se le hace tacto, se le espera o está por venir... Eso puede verse en una extraña o contradictoria cita que Bárcena (2005) realiza y aquí resulta importante repetir:

Nadie se desarrolla por juicio, sino por una lucha que no implica ningún juicio (...). El juicio impide la llegada de cualquier nuevo modo de existencia. Pues este se crea por sus propias fuerzas, es decir por las fuerzas que sabe captar, y vale por sí mismo, en tanto en cuanto hace que exista la nueva combinación. Tal vez sea este el secreto: hacer que exista, no juzgar. (Deleuze, 1996, pp. 187-188)

Pero, para Bárcena, a contracorriente del pasaje citado, hacer que exista lo nuevo en la existencia sería posible por los "juicios reflexionantes" que no tendrían un fundamento claro para juzgar y requieren de reflexión sobre la situación específica, el caso concreto, en un espacio y tiempo determinados en los que pensamiento, imaginación ${ }^{6}$, deliberación y juicio se equipararían en el proceder de alguien que se pone en el lugar de "todos los demás” (Bárcena, 2005, p. 184), valiéndose de cierta representatividad. Además de recordar (o promover) al

5 En El Anticristo, Nietzsche (1997) señala la doctrina del juicio como el invento del cristianismo, en particular de Pablo, para lograr la tiranía sacerdotal y formar rebaños a partir de conceptos y símbolos con los que tiranizar a las masas.

6 En un libro dedicado a Hannah Arendt, Bárcena (2006) sostiene que la imaginación prepara el terreno de la actividad reflexiva del juicio y es necesaria cuando se juzgan objetos que ya no están presentes o están alejados de la inmediata percepción sensible. Por la imaginación y la operación reflexiva (que "considerando" o representándose los puntos de vista de los demás formarían un "pensamiento representativo" para Arendt) se accedería a la "condición de la imparcialidad" como "placer desinteresado" que posibilitaría juzgar en posición de "espectadores desapegados”, distanciados de la situación o del objeto. ¿No subyace aquí precisamente la razón evaluadora con su pretensión de imparcialidad que esconde un goce pretendidamente desinteresado, desapegado o distanciado pero que no deja de estructurar los escenarios del juicio educativo de modo tal que la imaginación y la reflexión se supeditan a hacer de las singularidades meros objetos transicionales de su perversión? 
imperativo categórico kantiano, ese que rezaba obrar de manera tal que el principio de la acción pueda ser una máxima universalizable (el universal estaría ausente, pero es a lo que se tiende o aspira en la combinatoria), se enfatiza el sentido común (recordar a Gadamer) donde se asentaría un juicio (a priori) que sería representativo de todos los demás juicios (y valoraciones) y que se obtendría "comparando el juicio propio con el resto de juicios posibles sobre el mismo asunto, y obligando a la mente a adoptar el punto de vista de los demás, extendiéndola o alargándola más allá del lugar que ocupa" (Bárcena, 2005, pp. 185-186).

Ese último procedimiento, algo iluso o fantasioso, que no hace más que poner al Yo en el lugar de todos los demás, es lo que Bárcena (2005) llama, siguiendo a Kant, el pensamiento "alargado" -donde se apartaría de las condiciones subjetivas y adoptaría un punto de vista universal-, una modalidad del entendimiento que implica "pensar en el lugar de cada otro" (p. 186). Una canallada o vileza que ciertamente se diseminó por el mundo hace poco más de cinco siglos y hoy todavía se escucha (o se recicla) cuando se apela a la trillada frase de "ponerse en el lugar del otro" y que Nuria Pérez de Lara señala como un falso desplazamiento porque lo único que se hace es pensar una fantasía, pensar en aquello que solo puede imaginarse "reduciendo la realidad de los demás a nuestra propia fantasía” (en Skliar, 2011, p. 107). Por esto se coincide con Skliar (2015) cuando afirma: "El lenguaje que juzga está gravoso, carga el peso de siglos de humillaciones" (p. 48) y se reactualizan cada vez que se escuchan enunciados embestidores del tipo: yo en tu lugar..., lo que debería(s) ser o hacer..., lo que sería correcto...

Un párrafo aparte podría dedicarse a esa idea del sentido común como fuente del juicio representativo ya que lo común queda indiscutido y, como advierte Skliar (2011), tiene un poco de universal, pero como también está en juego la palabra comunidad, lo universal acaba siendo lo particular. Y ese común que sería base de un juicio supuestamente representativo está lejos de comprenderse como aquello que se opone a la tiranía del Uno, sea como fuere que este se presente -ya que Kant (1977) involucra hasta la imaginación para representar lo ausente o lo que los sentidos no permiten captar, así como a Arendt (1995) le permite ver y comprender "sin parcialidad ni prejuicio" o "colmar el abismo" de lo que está demasiado lejos pudiendo verlo como si fuera familiar-. Siguiendo esta línea, Bárcena (2005) indica el pensar propio "sin prejuicios" y "al margen" de juicios heredados o tradicionales, así como el pensar consecuente sería uno del tipo coherente en la consistencia lógica (siempre relativa al logos), pero el pensar alargado sería el capaz de hacerlo “en el lugar de todos los demás” y desplazándose más allá del reducto que le corresponde.

Cabría entonces preguntar si precisamente esta combinatoria de "modalidades del pensar" anudadas no serían la base del pensamiento colonial, o de la colonialidad del pensar, pues se considera imparcial, impoluto de prejuicios y parcialidades, consistente en relación con el logos y capaz de desplazarse hasta ocupar el lugar de "todos los demás”, ¿no fue este acaso el "fundamento" epistémico del pensamiento totalitario del siglo XVI al siglo XX? Aunque Arendt (1999) atribuya al genocida Eichmann una ausencia de pensamiento, y Bárcena (2005) relacione el pensamiento, la atención y la reflexión con la facultad de juicio para distinguir lo bueno y lo malo o actividad-condición para "no hacer el mal", ¿tal operación no posiciona la actividad del pensar en un lugar inmaculado a la vez que la reduce al juicio? (con su debido proceso, sentencia y condena). ¿No fue el exceso de ello precisamente lo que estaba potenciado en la razón de conquistadores y genocidas? ¿O para "salvar" la herencia de pensamiento kantiano y la racionalidad del juicio se dirá que allí no había pensamiento propio (pretensión de imparcialidad, objetividad, deslinde de tradiciones), consecuente (consistencia lógica) y alargado (capaz de ocupar -hasta destruir- el lugar de otros, sin supuestas complicidades subjetivas y con máximas pretendidamente universales)? ¿No es la racionalidad del juicio la que supone criterios preexistentes ("valores superiores" o "universales") desde siempre y de modo que no da lugar a la invención en la existencia?

7 Un enunciado que Bárcena (2005) acepta y refuerza incluso citando a Adam Smith (en La teoría de los sentimientos morales) cuando sugiere realizar la misma operación de "buena conciencia". 
Incluso desde una perspectiva cartesiana básica, afirmar que un genocida no pensó al hacer lo que hizo, no solo es despojarlo de existencia (una existencia que, por otra parte, pesó sobre las vidas con las que acabó) sino de las creencias, los deseos, propósitos e intenciones que constituyeron su juicio en pensamiento y acción. Pues como el mismo Bárcena (2005) reconoce, el juicio está ligado a la relación medios-fines y a la conexión que lo intermedia entre la deliberación (proceso) y la decisión (sentencia o condena), es lo que Kant (1984) refería como "mediación" (característica del juicio práctico) a partir de la cual un acto de la facultad de juzgar se añade al concepto del entendimiento que contiene la regla y determina si un caso cae o no bajo ella -lo cual evidencia la sospecha de Deleuze (1996) sobre los criterios preexistentes que siempre supone el juicio y recuerda su interpelación sobre qué juicio (por experto o específico que se considere) podría referirse a la obra/acción venidera. La entrada a escena de Dewey podría responder la pregunta deleuziana y mostrar ese juicio respecto al futuro en lo que de incompleto o indeterminado puede alojar en materia de situaciones. Se trata de los juicios prácticos, que para Dewey son también morales, viables para situaciones evaluativas que requieren decisiones sobre acciones concretas no sin riesgos, cuyas características formales Bárcena (2005) puntúa y comenta:

a) se elaboran en el ámbito de lo contingente, justo porque a través de ellos se conforma una situación problemática (...), tienen una lógica específica, sólo comprensible desde la situación concreta en la que se elaboran y a la cual responden. Son juicios que (...) personalizan; b) son factores de cumplimentación de una situación. Gracias a ellos la situación acaba siendo verdaderamente significativa para el agente; c) por ello mismo, (...) el modo en que se determine la situación -hacia mejor o hacia peor- es crucial. Buscan la mejora de la práctica; d) todo juicio práctico (...) requiere una clara percepción de los fines -el conocimiento de los fines opera como previsión de la accióny un análisis de los obstáculos y de los medios que permitan alcanzarlos; e) su carácter es hipotético, de modo que (...) se validan o invalidan por las consecuencias que desencadenan. Son actividades como la educación las que precisan de los practicantes un cierto grado de imaginación para que los juicios reflexivos puedan operar como tales. Existen innumerables posibilidades de acción, decisión y movimientos, como en el ajedrez. Desde luego -como en este juego-, hay determinadas reglas básicas; son las normas sin cuyo conocimiento no es posible practicarlas. (...) Los juicios prácticos, en definitiva, necesitan ser reflexivos, y todo juicio ocupa un lugar central en la actividad reflexiva (pp. 197-198, énfasis mío.)

Esta caracterización resulta importante para entender de qué maneras la razón evaluadora recicla en su interior las lógicas del juicio y sus variantes, evidencia su refinamiento en el tratamiento de lo contingente y la posibilidad de recrear su lógica a partir de una situación determinada, como en una suerte de evaluación personalizada. De esa manera, sus factores establecen pautas o legalidades de cumplimiento que por afirmación o negación tienden a marcar significativamente al sujeto en cuestión, siempre en relación con un imperativo de "mejora" que ratifica la relación medios-fines (a la que se limita la acción para mera consecución de un fin). La correlación entre su carácter "hipotético" y las consecuencias producidas, habilita la sospecha sobre esa validación o invalidación a posteriori a la vez que permite rodear de interrogantes lo hipotético una vez que "la sangre llega al río".

Que dicho juicio requiera de imaginación e innumerables posibilidades de acción, decisión y movimientos estratégicos en función de normas, recuerda que en la lucha contra el juicio "los gestos son defensas o incluso ataques, regates, fintas, anticipaciones de un golpe que no siempre se ve llegar, o de un enemigo que no siempre se consigue identificar" (Deleuze, 1996, p. 184), y aunque las normas se pretendan centro de gravedad o "eje divino a partir del cual todo se ordena y organiza, todo se cataloga y clasifica, todo se nombra y define" (Skliar, 2011, p. 106), hay que renunciar a todo vestigio de su producción, a todo vestigio de normalidad. Y ensordecerse, enceguecerse, paralizarse, comunizarse, olvidarse, tartamudearse, afectarse, imposibilitarse, para que "lo normal" y "la normalidad” (producto de todo juicio y norma) deje de ser o de creer ser, de una vez por todas, ese fatídico centro del universo educativo. 
Se trata de dislocar o desarticular el juicio del centro de la actividad reflexiva y con ello del centro de la actividad educativa, muy a contracorriente de Dewey (2007), para quien "la totalidad del proceso de pensar se reduce a formar una serie de juicios relacionados de modo tal que se sostienen mutuamente conduciendo a un juicio final: la conclusión” (p. 22); y de Bárcena (2005), para quien "sin juicio no hay posibilidad de resolver la acción en el contexto de la práctica" (p. 198), porque juzgar es "seleccionar y sopesar" hechos (para ver si lo son), sugerencias e ideas (para ver si son sólidas o meras fantasías), y otorgaría capacidad de discernir, "de estimar, apreciar y evaluar con tacto" (p. 199). Una operación tal vez fundamental sea ya no solamente interrumpir la sinonimia -instalada por la modernidad/colonialidad- entre educación y evaluación, sino también entre pensamiento y juicio. Se trataría entonces de no ceder al juicio (por más pedagógico o reflexivo que se pretenda) incluso en las condiciones que lo hacen posible, por ejemplo, allí donde el juicio promete mirada donde no se ve claramente -ya sea por algún estado de controversia, de complejidad o de confusión-, o allí donde la información junto al conocimiento impone un manejo, un orden, una organización y una distribución que hacen de los fragmentos del "rompe-cabezas" una imagen significativa. Y aunque "no existan reglas fijas de actuación” (Bárcena, 2005, p. 199), se sabe que siempre está en juego un proceso de selección que escoge lo significativo para dicha lógica y rechaza lo que considera accesorio o irrelevante, más allá de que se mueva sobre un suelo de provisionalidad donde las elecciones puedan cambiar según las cotizaciones.

Por lo demás, la trayectoria de la pena suele ser conocida: se va del juicio a la decisión que sentencia o condena, pero que no se ceñiría al caso particular, sino que debería:

contribuir a fijar, mediante habitus, reglas de actuación futura y ulteriores normas de aplicación cuya garantía de éxito tiene por fundamento la propia experiencia crítica del individuo. Ello permite ir generando, gradualmente, principios de actuación y de procedimiento, así como estandarizar significados". (Bárcena, 2005, pp. 199-200)

Todo pareciera apuntar así a hacer de la educación un estricto ámbito jurídico, un lugar para la jurisprudencia, para un conjunto de fallos y sentencias que intentarían la fijación de normas de pre-visión y cálculo cuya "garantía de éxito” tendría fundamento en la experiencia crítica. Ni en la crítica de la experiencia, ni en la experiencia de la crítica, solo la experiencia crítica, tal vez ese extremo decisivo donde todo requeriría o justificaría una evaluación en medio de la crisis que ella misma genera (como el propio capitalismo).

Dicho deber de "contribución" mediante "habitus" deja al descubierto una noción que puede remitir a la traducción latina que parte del cristianismo hizo (de la mano de Tomás de Aquino y Boecio) de la hexis aristotélica -ese concepto intermedio entre la potencia y el acto, entre el interior y el exterior- o a uno de los ejes centrales de la sociología bourdieana según el cual se trataría de disposiciones o esquemas de pensamiento y acción asociados a una posición social determinada (cuyo entorno es considerado mayormente homogéneo) desde la cual se evalúa el mundo en función de ciertos recursos y estrategias atados a estos. Si bien ambas nociones parecen estar involucradas en la propuesta en cuestión, la tendencia sociológica pareciera tener cierta primacía desde el punto en que se apunta a fijar reglas y normas mediante habitus que, en clave bourdieana, serían aquellos esquemas generativos a partir de los cuales los sujetos perciben el mundo y actúan en él en función de su clase social (lo que naturaliza de hecho la reproducción social reificada, por ejemplo, en el gusto y que no considera prácticas de resistencia).

Por lo tanto, el juicio y su sentencia no quedarían restringidos al ámbito de lo particular sino cual imperativo categórico se los impulsa a sentar normas (o precedente y

8 Tanto los principios de actuación y procedimiento como la estandarización de significados ubican al juicio -en cualquiera de sus variantesen territorio de la moral ya que, como ha demostrado Mèlich (2014), esta se caracteriza por crear, justificar, explicar, significar y, sobre todo, legitimar. En su "poder de legitimación” radica su peligrosidad y su lógica cruel se manifiesta en el significado que otorga en sus procedimientos con sus ineludibles efectos de reconocimiento, clasificación, ordenamiento, inclusión/exclusión. 
jurisprudencia) para futuros casos y con ello confirmar que el juicio, por práctico o reflexivo que se pretenda, tiene un afán generalizador, normalizador y jurisprudencial con gravidez hacia el futuro. De aquí que pueda entenderse mejor lo dicho con anterioridad sobre los criterios preexistentes que son base del juicio e intentan referirse a la acción/obra venidera aún sin siquiera esta consumarse. De alguna manera podría decirse que este funciona por anticipación (como un pre-juicio demasiado literal), y esto reclama un gran cuidado ético-político si de educación se está hablando.

\section{El tacto y la altura de la razón evaluadora}

Precisamente por todo lo que se viene mostrando y analizando es que no se puede reducir la educación a un sistema penal o a una corte productora de (pre) juicios. Tal vez sea tiempo de desmantelar los tribunales de la educación y que lo venidero pueda existir sin más juicio en la trama de cierta enseñanza, alteridad y ejercicio estudiantil. Principal modo, quizá, de que la enseñanza y la competencia no se pongan a la misma altura cuando una experiencia político-pedagógica está en juego. De lo contrario, la actividad educativa en su singularidad irreductible queda sometida al juicio y su afán de "comprensión" -ese afán de componer y totalizar, como enseñó Kusch (2007)-, reduciendo la actividad docente a la actividad de juzgar como búsqueda de una "idea regulativa" y "modo de hacer experiencia cuando una situación irrumpe” (Bárcena, 2005, pp. 200-201). Es cuando entraría a jugar la idea de "tacto educativo", consolidando el juicio como praxis pedagógica, que Bárcena (2005) toma del neokantiano alemán Joan Friedrich Herbart y quien lo caracteriza como regla inmediata de la práctica, sensible a la singularidad de las situaciones, que se manifiesta en la cotidianeidad de formular juicios en situación. Ahora bien, la idea se complejiza un poco más cuando profundiza en la concepción del pedagogo holandés Max Van Manen (1998) y agrega una serie de cualidades y habilidades al tacto: ...saber interpretar los pensamientos, interpretaciones y sentimientos del otro (capacidad para ver a través de los motivos de la conducta ajenos o de las relaciones causaefecto; lectura de la vida interior de otro, etc.); capacidad para interpretar la importancia psicológica y social de las características de la interioridad del otro (habilidad para interpretar el significado profundo de cosas tales como la timidez, la frustración, etc.); capacidad para juzgar apropiadamente en situación, para aplicar normas o reglas. (Bárcena, 2005, pp. 203-204)

El planteamiento contiene implícita una definición del otro como un texto manifiesto, transparente y legible que solo habría que "saber interpretar" o leer de acuerdo con relaciones causales que motivarían su conducta o posibilitarían juzgar su interioridad. Esto toma mayor notoriedad en esta época donde las propuestas de "educación emocional" tienden a legislarse y se proponen desarrollar la habilidad de detectar y evaluar los pensamientos y diálogos internos de estudiantes y docentes como "capacidad socio-afectiva y espiritual" de "autoconocimiento". En este sentido, no está de más la advertencia que Bárcena (2005) realiza sobre el sencillo devenir del tacto en garra que identifica y clasifica. O tal vez será que cuando el tacto lleva implícita la actividad de juzgar, lejos está de proveer caricia y cerca está del rasguño que deja marca. Porque difícilmente el "tacto educativo" con juicio implícito pueda permitir "experimentar la subjetividad del otro sin alterarla", lo que incluso la caricia misma (desprovista de teleología como puede estar) no logra cometer ya que el mínimo roce dispara algún sentido y altera algún estado.

No es difícil sospechar entonces del tacto educativo planteado como "reconocimiento del otro" que posibilitaría "actuar por el bien del otro" (Bárcena, 2005, p. 205), algo que recuerda a Alice Miller (1998) cuando, en su clásico libro "Por tu propio bien. Raíces de la violencia en la educación del niño", ya evidenciaba la crueldad de la educación moral y sus mandatos de "amor al prójimo",

9 A modo de ejemplo podría verse el documento titulado "Líneas de política educativa provincial para el enfoque de desarrollo de capacidades socio-afectivas y espirituales en el sistema educativo de Formosa”, cuyos lineamientos, alcances y objetivos forman parte de la resolución No 0536 del Ministerio de Cultura y Educación de la Provincia de Formosa (Argentina, 11/o2/19). 
altruismo y “espíritu de sacrificio”. Miller (1998) sostiene allí que la máscara de amabilidad ayuda a ocultar aun mejor la crueldad del tratamiento y ejemplifica con un docente que logró que sus estudiantes le obedecieran sin necesidad de golpes convenciéndolos de que está actuando "por su propio bien" y demostrándoles, mediante ejemplos y comparaciones, que ellos serán los primeros perjudicados si no obedecen. Matriz compartida también por el docente que ofrece un discurso melancólico al final de la clase, luego hace pasar al frente (reconociendo) a quien lo desobedece, lee su sentencia y pregunta si sabe por qué es merecedor/a de ella, e inmediatamente le aplica el castigo en forma (de reconocimiento) "ejemplar". Así, se entiende más aun la necesidad de compartir la radical oposición al "reconocimiento del otro", como Skliar (2017) que lo sostiene precisamente porque el otro es anterior a todo reconocimiento y si así no fuera "sería como una estatua cubierta por una tela negra en una plaza abandonada, esperando a ser descubierta. O como un territorio que creemos inexistente y al que damos un nombre que no es el suyo" (p. 165).

Finalmente, Bárcena (2005) insiste en que la "última lección” o el último juicio estará en manos del discípulo, un giro que pone al juzgado en situación de juzgar y muestra un procedimiento típico que será reciclado y potenciado en la racionalidad evaluadora: todo evaluado será un evaluador en potencia. Algo que quizá podría observarse en su libro dedicado a Hannah Arendt, donde recicla o repite el ensayo que se analizó recién, sin rectificar más que algunos detalles menores de su contenido, pero orientándolo ahora a la idea arendtiana del "espectador juicioso"; partiendo nuevamente de la idea de la tradición humanista como "defensora de la facultad de juzgar”, desde el ángulo de su historia intelectual menciona la presencia del juicio como "omnipresente y elusiva al mismo tiempo” (Bárcena, 2006, p. 228).

Asimismo, las referencias mencionadas incluyen nombres clásicos del canon occidental, de Platón a Aristóteles, pasando por Tomás de Aquino, Vico, Spinoza, Kant, Hobbes, Locke, Shaftesbury, Hume, Burke, William Godwin, Arendt, entre otros. Enmarcado en tal tradición, sostiene cierta noción de humanidad afincada en la constancia de formular juicios en cualquier campo o dominio y a lo largo de la vida. Lo que aquí interesa observar es cómo finalmente reconoce, siguiendo a Steinberger, que el juicio termina por ser una actividad en virtud de la cual predican universales de particulares y "significa siempre discernir o distinguir con atención a un medio o a una norma", aspecto que lo conduce a distinguir tres significados principales del juicio: a) como operación lógica mediante la cual se afirman o niegan proposiciones; b) como facultad cognitiva o "esfera inequívoca de la actividad mental”; c) como facultad práctica o "juicio prudencial" (Bárcena, 2006, pp. 233234). Aunque su interés se enfoque en esta última, ¿hasta qué punto puede ignorar o desprenderse de las otras dos? ¿No será acaso que tal facultad práctica o prudencia del juicio no pueden ejercerse sin lo que se afirma a base de la negación de la alteridad o lo que se niega a base de la afirmación de lo mismo, siempre en favor de cierta esfera política considerada inequívoca?

La resolución de dicho problema ético-político sería una cuestión de imaginación, ya que por ella se logra la "condición de imparcialidad" que se obtendría "considerando los puntos de vista de los demás" (Bárcena, 2006, p. 241). Una vía más cerca de ser una solución pos-política o de lógica consensual, que intenta saltear o reducir la disputa, en lugar de dar paso a la construcción política que todo antagonismo suscita. Esto mismo puede verse también cuando sigue a Beiner (1987), quien frente a la pregunta “¿Kant o Aristóteles?” sostiene que "un entendimiento general del juicio humano sería incapaz de prescindir de alguno de los dos" y promueve una perspectiva "capaz de abarcar al mismo tiempo autonomía y teleología” (p. 173). Ello no solo carece de exterioridad por conducir a un callejón sin salida del pensamiento occidental, sino que también enseña la compatibilidad existente incluso entre paradigmas diferentes (que hunden de distinto modo su raíz en la colonialidad del ser, del saber y del poder).

Como esa cuestión no es atendida, la función del juicio aparece como la que "enraizaría" a las personas en el mundo (aunque no se aclara en qué mundo), que carecería de sentido y realidad existencial si no fuera por el juicio, lo que desde tal perspectiva hace "inalienable" al "derecho de juzgar" (Bárcena, 2006, p. 252). Del 
mismo modo, últimamente se plantea el "derecho a la evaluación”, que consistiría en focalizar la formación para atravesar la experiencia de evaluación (convertida ya en objeto de enseñanza) instituida como "necesaria" para el "desarrollo de trayectorias educativas", y que constituye hasta la calificación un derecho en tanto y en cuanto comunica en forma sistemática un juicio de valor expresado en una escala determinada que permitirá tomar decisiones en función de la medición del aprendizaje y sus progresiones ${ }^{10}$. La trampa está en que estos deberes o imperativos disfrazados de "derechos" serían garantes de las prácticas de enseñanza sobre las que el Estado asumió su responsabilidad, tiñendo la evaluación de enseñanza y confundiendo nuevamente educación con evaluación.

$\mathrm{Si}$ "Arendt se fue convenciendo de que esta facultad de juicio es un patrimonio común de los hombres dentro del mundo público, en el que aúnan las cualidades del actor político y del espectador desinteresado" (Bárcena, 2006, p. 252), puede que sea cierto entonces lo que dijo una docente cierta vez sobre que atacar la razón evaluadora (o el juicio por extensión) en educación es meterse con el patriarcado pedagógico, otra manera de decir que ese patrimonio no es (tan) común y que el mundo público también está perforado por actores desinteresados y espectadores políticos, así como por actrices políticas y espectadoras interesadas al mismo tiempo. Porque un mundo donde caben muchos mundos no depende del juicio para existir o hacer sentido, sino del cuidado, de la atmósfera, del sentido y el subversivo calor que lo popular le puede dar.

No se juzga porque se ve, ni porque se sea el mundo, se juzga porque los sentidos están formados en una lógica moral ineludiblemente cruel contra la que hay que luchar, y se juzga cuando alguien se cree el (centro del) mundo. Tal vez por eso sea mejor descentrarse y así dar lugar a lo ex-céntrico o relacionarse como excentricidades hasta que no haya centralidades ni centrismos. Porque el mundo está, meramente está, aun cansado de tanta transformación acelerada. Y aunque se diga que "Sin juicio, el mundo carecería de valor” o que la facultad de juzgar es la que ratifica el domicilio en el mundo, aun cuando no se disponga de un fundamento claro, la que posibilita "dar sentido a lo que nos pasa y a lo que hacemos” (Bárcena, 2006, pp. 253-254), siempre podrá recordarse el Crepúsculo de los ídolos cuando se subraya que "el valor de la vida no puede ser tasado" (Nietzsche, 2013, pp. 54-55), y que se podrá dar al mundo cosas más saludables e interesantes que valor (pues para este ya están los mercados y sus juzgados).

Nadie, o muy poca gente, desea vivir en el mundo de los tribunales, allí donde confirman ser jueces quienes están abocados a una existencia que requiere necesariamente de sospechados, culpables y condenados, allí donde el juicio confirma que se está y se es siempre a costa de otros. Y es por esto que la facultad o capacidad de juicio da significado o sentencia (y no sentido) a lo que pasa y a lo que se hace, porque se trata de una lógica moral y no de una interpelación ética. Resulta incluso singular cómo puede insistirse en relacionar tan amablemente "lo que nos pasa" con "estar a la altura", una especie de prueba por la que "tendríamos" que pasar y que tiene su propia medida o "elevación", a la que "convendría" ser equivalentes para supuestamente no caer en la banalidad, la mediocridad o el resentimiento:

Se trata de no estar ni por encima ni más abajo del acontecimiento, que es eso que nos pasa, la prueba por la que tenemos que pasar, nuestra singular travesía. Se trata simplemente de estar a su misma altura, porque lo que nos pasa tiene su propia medida y su propia elevación. Y conviene ser equivalente a esa dignidad, a esa altura, para no caer ni en la banalidad, ni en la mediocridad, ni en el resentimiento. (Bárcena, 2012, p. 258, énfasis mío)

Skliar (2014) piensa que "estar a la altura" más que una frase típica en educación es una sensación que recorre la vida y una pretensión que recomienda abandonar por su grado de nocividad, peligrosidad y sometimiento, ya que enfrenta a circunstancias que, en el fondo, son meras exigencias. Como si, por el mero hecho de pronunciarla,

10 Un ejemplo de este planteo en materia jurídica se podría encontrar en la resolución № 1057 de la Dirección General de Cultura y Educación de la Provincia de Buenos Aires (Argentina, 7/07/14). 
de frase pasara a un imperativo insoportable que exige altura de aeronave militar cuando no se puede despegar los pies del suelo de la infancia.

Cuántas biografías escolares han sido atravesadas por la inoculación de la decepción que reza: "no he estado a la altura”. Cuánta prepotencia, en lugar de docencia, se recalca todo el tiempo al exigir: "Tienes que estar a la altura”. Y es cierto: evaluar tal vez sea medir la altura, por eso se hace del acontecimiento prueba y de lo que con él (nos) pasa medida de elevación que pide equivalencia (y no diferencia). La trampa quizá está en pensar que esa elevación, esa "altura", sería una dignidad que pone a salvo de la banalidad, la mediocridad o el resentimiento. Como si en las alturas no se encontraran banalidades elevadas, supremacías mediocres o resentimientos supremos y se olvidara que, en la bajura, además de profundidad, también se encuentra lo cardinal, lo sublime y la ternura. Pero, no para no perderse entre falsas dicotomías o entretenidas aporías, se pordría afirmar con Skliar (2014) que nunca, jamás, se está a la altura porque esta siempre se mueve, como la idea de normalidad que, cual monstruo metamórfico, apenas se le cree conocer ya cambia su forma e incrementa su alto, su largo, su con-textura y complejidad. Por eso quizá no estaría de más aguzar el sentido del vértigo cuando pasa por el cuerpo y, más aun, por un cuerpo enseñante: un síntoma que no pide (a otros y a sí) estar a la altura, sino, tal vez, dejar en paz. Esta sería la paz popular de la que habla Illich (2008), la que reclama la gente desde los márgenes, la que la máscara del desarrollo le planta guerra hasta en estos días para imponer la paz económica.

Y no hay paz económica sin razón evaluadora, algo que Bárcena sabe cuando señala que la economía del dinero reduce la vida a la evaluación, la ponderación, el cálculo y su tiempo vital al ajuste del reloj: "tiempo cronometrado, puntual, matemático, calculado, previsto y previsible" (en Bárcena y Mèlich, 2014, p. 212). Aun así, hay quienes insisten en que lo enseñado debe mostrar correspondencia en un supuesto "aprendizaje" a demostrar en tiempo y forma, evaluación y examen, que abrirá un juicio tanto como cancelen algo vital de la existencia: el improbable aprender que requiere perder tiempo en signos y que es radicalmente opuesto a la mera asimilación de contenidos.
Quien exija un aprendizaje porque "sabe" con certeza cómo aprende alguien, está más cerca de cometer un crimen que de convidar una enseñanza, porque así es como se aniquila un enigma indescifrable o un misterio histórico, en lugar de sostener y alimentar toda la alteridad que irradia su incógnita.

\section{Colofón: desarmando escenarios}

Para Artaud (2013), escribir, como hacer poesía, se anudaba a movimientos tales como salir, sacudir, atacar -y más si encontraba (pre)juicios en alguna parte-. La música de este ensayo ha intentado provocar esos movimientos e introducir algunas dislocaciones pedagógicas en un sistema colonizado por la razón evaluadora. Un sistema que obliga a engullir y a vomitar, que promueve un aprendizaje bulímico, es el que aquí se intenta combatir. Porque asumir lo político de la educación, también es asumir los antagonismos y las luchas que la constituyen: esas brechas irreductibles que separan el educar del evaluar, la singularidad del comparar, la lectura del juzgar, la ética de la moral.

Sobre el "no hay tiempo que perder" y no hay lugar para distraerse, desatender, dormirse para volver a despertar con otros ojos y otra respiración (movimiento que puede valer una etiqueta psicopatológica o un saldo deudor como castigo por una falta), se montan los escenarios del juicio educativo. Escenarios cuyas fuentes literarias pueden alertar sobre la instalación de deudas con las que el poder de juzgar somete, avasalla, organiza y circula. Hasta un placer de juzgar y ser juzgado se erige como seducción de un loteo circular en el que las (ab)soluciones suelen ser aparentes, pero siempre intolerantes a la obstinación, la tozudez, la indomabilidad, la terquedad o la porfía.

La inscripción de la pedagogía y la educación en la facultad de juzgar, no solo se conforma con "mirar lo que hay", sino con naturalizar oposiciones (como mirar/actuar o actividad/pasividad) que embrutecen en tanto instalan cosificaciones calculables que no ayudan a los sujetos de la educación a saberse actores y espectadores de una trama comunitaria. La filosofía subyacente de estos escenarios se combina con intervenciones pedagógicas montadas sobre diferentes tipos de juicios cuyo rasgo compartido 
es una pretensión de imparcialidad que esconde su goce estructurante y que hace de las singularidades meros objetos transicionales de su perversión. De este modo, los escenarios del juicio educativo justificados desde cierta filosofía y pedagogía ponen la imaginación al servicio del poder evaluador y entronizan el Yo que facultan para ponerse en (u ocupar) el lugar de todos los demás. Es así como llega a verse la colonialidad del pensar, que reduce toda reflexión a algún tipo de juicio y avasalla el porvenir con su afán de normalidad.

Si no se quiere ser más espectador y/o actor del teatro de la crueldad, un primer movimiento podría tener que ver con no aceptar las cosas "tal y como son”, seguido de cuestionar lo dado y entrever su formación cultural, al tiempo que una lucha se traza contra las fuerzas del juicio que intentan anular cualquier proceso de liberación. Si la razón evaluadora divide la existencia, una corporalidad afectuosa, intensa y anárquica le dará batalla en sus polos, umbrales y zonas en los que el tacto incluye esa garra que identifica y clasifica.

El esfuerzo poético en desmantelar los tribunales de la educación es una forma de dar tiempo y lugar a que lo venidero pueda existir sin más en el contexto de cierta enseñanza, alteridad y ejercicio estudiantil. Una manera tal vez de que el patriarcado pedagógico no se salga con la suya, que no deje más muertes en el camino y puedan hilvanarse otras tramas aun "en el medio de la fiesta de los egos, los ninguneos, las ausencias, el des-abrazo” (Shock, 2018, p. 13). Tramas que tejan comunidad y no cierren la puerta cuando afuera (o adentro) hay una tempestad: un arte de la docencia, podría decirse con Wayar (2018), que potencie espacios de libertad en la intriga, en la búsqueda, en el conmoverse con el cuerpo, ahí donde está precisamente la cuestión nodal de la infancia.

\section{Referencias bibliográficas}

Arendt, H. (1995). De la historia a la acción. Barcelona: Paidós.

Arendt, H. (1999). Eichmann en Jerusalén. Un informe sobre la banalidad del mal. Barcelona: Lumen.

Artaud, A. (2013). Para terminar con el juicio de dios. El teatro de la crueldad. Buenos Aires: El Cuenco de Plata.

Bárcena, F. (2001). La esfinge muda. El aprendizaje del dolor después de Auschwitz. Barcelona: Anthropos/Guadalupe N.L.: Universidad Autónoma de Nuevo León.

Bárcena, F. (2005). La experiencia reflexiva en educación. Barcelona: Paidós.

Bárcena, F. (2006). Hannah Arendt: una filosofía de la natalidad. Barcelona: Herder.

Bárcena, F. (2012). El aprendiz eterno. Filosofía, educación y el arte de vivir. Buenos Aires: Miño y Dávila.

Bárcena, F. y Mèlich, J.-C. (2000). La educación como acontecimiento ético. Natalidad, narración y hospitalidad. Barcelona: Paidós.

Bárcena, F. y Mèlich, J.-C. (2014). La educación como acontecimiento ético. Natalidad, narración y hospitalidad (nueva edición revisada y aumentada). Buenos Aires: Miño y Dávila.

Beiner, R. (1987). El juicio político. México: Fondo de Cultura Económica.

Deleuze, G. (1996). Crítica y clínica. Barcelona: Anagrama.

Dewey, J. (2007). Cómo pensamos. La relación entre pensamiento reflexivo y proceso educativo. Barcelona: Paidós. 
Gadamer, H.-G. (1999). Verdad y método I. Salamanca: Sígueme.

Giuliano, F. (2019). ¿Tienes razón evaluación? Notas para la profundización de una noción filosófica de la educación. Revista Electrónica Educare, 23(1), 1-22. Disponible en: https://www.scielo.sa.cr/ pdf/ree/v23n1/1409-4258-ree-23-01-405.pdf

Illich, I. (2008). Obras reunidas II. México: Fondo de cultura Económica.

Kafka, F. (2013). Relatos completos. Buenos Aires: Losada.

Kant, I. (1977). Crítica del juicio. Madrid: Espasa-Calpe.

Kant, I. (1984). Teoría y praxis. Buenos Aires: Leviatán.

Kusch, R. (2007). Obras completas: v. 3. Rosario: Fundación Ross.

Lawrence, D. H. (2006). Apocalipsis. Buenos Aires: Losada.

Lezama-Lima, J. (1976). Paradiso. México: Era.

Mann, T. (2005). La montaña mágica. Barcelona: Edhasa.

Mèlich, J.-C. (2014). Lógica de la crueldad. Barcelona: Herder.

Mignolo, W. (2010). Desobediencia epistémica. Retórica de la modernidad, lógica de la colonialidad y gramática de la descolonialidad. Buenos Aires: Del Signo.

Miller, A. (1998). Por tu propio bien. Raíces de la violencia en la educación del niño. Barcelona: Tusquets.

Nietzsche, F. (1997). El Anticristo. Maldición sobre el cristianismo. Madrid: Alianza.

Nietzsche, F. (2000). El nacimiento de la tragedia. Madrid: Alianaza.
Nietzsche, F. (2013). Crepúsculo de los ídolos o Cómo se filosofa con el martillo. Madrid: Alianza.

Nussbaum, M. (1997). Justicia poética. La imaginación literaria y la vida pública. Santiago de Chile: Andrés Bello.

Orwell, G. (1995). 1984. Barcelona: Destino.

Rancière, J. (2010). El espectador emancipado. Buenos Aires: Manantial.

Ricouer, P. (1996). Sí mismo como otro. Madrid: Siglo XXI.

Shock, S. (2018). Prólogo. En: Wayar, M. Travesti. Una teoría lo suficientemente buena (pp. 13-15). Buenos Aires: Muchas Nueces.

Skliar, C. (2011). Lo dicho, lo escrito, lo ignorado. Ensayos mínimos entre educación, filosofía y literatura. Buenos Aires: Miño y Dávila.

Skliar, C. (2014). "Incluir las diferencias: una realidad insoportable" en Libro de actas I Congreso Internacional Barcelona Inclusiva 2014. Disponible en: https://www.copoe.org/images/ Congresos-Copoe/Barcelona_2014_Libro-ActasCongreso.pdf

Skliar, C. (2015). Desobedecer el lenguaje. (Alteridad, lectura y escritura). Buenos Aires: Miño y Dávila.

Skliar, C. (2017). Pedagogías de las diferencias. Buenos Aires: Noveduc.

Van Manen, M. (1998). El tacto en la enseñanza. El significado de la sensibilidad pedagógica. Barcelona: Paidós.

Wayar, M. (2018). Travesti. Una teoría lo suficientemente buena. Buenos Aires: Muchas Nueces. 